\title{
Perencanaan Strategis Sistem Informasi Menggunakan Ward And Pepper (Studi Kasus Dinas Perpustakaan Dan Kearsipan Salatiga)
}

\author{
Askar Wirawan ${ }^{1}$, Augie David Manuputty ${ }^{2}$ \\ ${ }^{1,2}$ Sistem Informasi, Fakultas Teknologi Informatika, Universitas Kristen Satya Wacana \\ ${ }^{3}$ Jl. Dr. O. Notohamidjojo No. 1 - 10, Kota Salatiga, 50714 \\ E-mail: ${ }^{1682016058 @ ~ s t u d e n t . u k s w . e d u, ~}{ }^{2}$ augiemanuptty@gmail.com
}

\begin{abstract}
Abstrak
Dinas Perpustakaan dan Kearsipan kota Salatiga merupakan salah satu instansi pemerintahan yang berperan aktif dalam pemanfaatan sistem informasi dan teknologi informasi dalam melaksanakan proses bisnis agar berjalan secara efisien. Untuk menjaga agar proses bisnis berjalan dengan efisien diperlukan perencanaan strategis sistem informasi. Penelitian ini menggunakan pendekatan kualitatif dengan kerangka kerja Ward and Peppard (2002). Tahapan tersebut terdiri dari tahapan pengumpulan data, proses analisis, dan tahapan keluaran. Tahapan pengumpulan data berisi gambaran kondisi lingkungan bisnis internal, kondisi lingkungan bisnis eksternal, kondisi sistem informasi internal organisasi dan kondisi sistem informasi eksternal organisasi. Beberapa metode analisis seperti SWOT Analysis, CSF digunakan untuk menganalisis lingkungan bisnis internal dan eksternal. Hasil dari penelitian ini yaitu rencana strategis SI/TI dan blueprint SI/TI yang akan dijadikan acuan dalam pengembangan SI/TI Perpustakaan dan Kearsipan kota Salatiga di masa depan.
\end{abstract}

Kata kunci: Perencanaan strategis, Ward and Peppard, SWOT dan CSF.

\begin{abstract}
Regional Library and Archives Office of Salatiga is one of the government offices which works actively in the use of information systems and information technology in implementing business processes to run efficiently. To keep business processes running efficiently, strategic planning of information systems is needed. This study uses a qualitative approach with the framework of Ward and Peppard (2002). These stages consist of data collection, analysis process, and the output. The data collection stage contains a description of the internal business environment condition, the condition of the external business environment, the condition of the organization's internal information system and the condition of the organization's external information system. Several analytical methods such as SWOT Analysis, CSF are used to analyze the internal and external business environment. The results of this research are IS/IT strategic plans and IS/IT blueprints which will be used as the references in developing IS/IT in Regional Libraries and Archives Office of Salatiga in the future.
\end{abstract}

Keywords: Strategic planning, Ward and Peppard, SWOT and CSF

\section{PENDAHULUAN}

Prkembangan Teknologi Informasi saat ini menjadikan kebutuhan manusia akan teknologi Pjuga semakin tinggi, dengan kemajuannya dari teknologi informasi memberikan semua pihak sumber informasi dan komunikasi yang amat luas, dengan adanya hal tersebut membuat pihak yang menggunakannya dapat menghasilkan informasi yang berkualitas yaitu informasi 
yang relevan, akurat dan tepat waktu, yang digunakan untuk keperluan pribadi, bisnis, pemerintahan dan merupakan informasi yang strategis untuk pengambilan keputusan semakin berkembangnya teknologi membuat perusahaan harus melakukan pengembangan dan pembangunan sistem informasi guna membantu aktivitas bisnis dan memberikan layanan kepada stakeholder terutama yang berhubungan dengan data, informasi, teknologi dan aplikasi.

Penelitian ini difokuskan pada penggunaan SI/TI pada Dinas Perpustakaan dan Kearsipan Salatiga untuk mendapatkan gambaran mengenai pengelolaan SI/TI dalam proses pelayanan. Dan juga mempelajari hambatan-hambatan yang dialami Dinas Perpustakaan dan kearsipan dalam penggunaan SI/TI. Oleh karena itu diperlukan perencanaan strategis SI/TI pada Dinas Perpustakaan dan Kearsipan Salatiga yang mampu menyelaraskan strategi bisnis dan strategi SI/TI agar dapat mencapai tujuan bisnis secara efektif dan efisien. Metode Ward and Pepper digunakan untuk melakukan perencanaan strategis sistem informasi pada Dinas Perpustakaan dan Kearsipan untuk membantu dalam pengelolaan dan pemanfaatan teknologi. karena tujuan utama perencanaan strategis informasi adalah mempersiapkan rencana bagi pengelolaan analisis, perancangan dan pengembangan sistem berbasis komputer. Metode perencanaan strategis SI/TI berdasarkan Ward and Peppard Model terdapat 2 tahapan yaitu tahapan input (masukan) dan output (keluaran) [1].

Penelitian dengan topik Perencanaan Strategis Sistem Informasi Menggunakan Ward and Pepper bukanlah merupakan topik baru, maka beberapa penelitian terdahulu dijadikan acuan dalam penelitian. Penelitian dilakukan Ferry Wibowo, Agustinus Fritz Wijaya (2018) berjudul "Perencanaan Strategis SI/TI Menggunakan Metode Ward and Peppard" (Studi Kasus: Sinode Gkj). Dalam penelitian tersebut mengatakan Sinode Gereja Kristen Jawa (GKJ) saat ini masih belum menerapkan sistem informasi/ teknologi informasi (SI/TI) di organisasi. Permasalahan lain dalam penerapan SI/TI di organisasi nirlaba adalah menyangkut investasi SI/TI yang masih belum memberikan manfaat yang diharapkan kepada organisasi. Perencanaan strategis SI/TI dengan menggunakan metode Ward and Peppard merupakan proses identifikasi portofolio aplikasi berbasis komputer yang akan mendukung organisasi dalam pelaksanaan rencana bisnis dan merealisasikan tujuan bisnisnya. Penyusunan SI/TI di Sinode GKJ memberikan keselarasan antara SI/TI dengan visi, misi, dan tujuan Sinode GKJ karena portofolio solusi SI/TI disusun berdasarkan hasil kajian dan analisis terhadap aktivitas utama dan aktivitas pendukung yang diidentifikasi menggunakan value chain activity [2]

Penelitian dilakukan Danton Wandikbo dan Melkior N.N Sitokdana (2019), berjudul "Perencanaaan Strategis Sistem Informasi di Yayasan Binterbusih Semarang Menggunakan Ward and Peppard" Yayasan Binterbusih Semarang adalah organisasi non-profit yang bergerak dibidang pendidikan,pembinaan dan pelatihan khusus putra-putri Papua di wilayah Jawa dan Bali. Yayasan Binterbusih bekerjasama dengan beberapa pemerintah kabupaten/kota di Tanah Papua dan Yayasan Binaan PT. Freeport Indonesia. Dalam menjalankan program tersebut Yayasan Binterbusih mengalami berbagai persoalan, yaitu pengelolaan administrasi, pengelolaan data penerima beasiswa, pelaporan, pengelolaan keuangan, pengelolaan aset, pengelolaan SDM masih dilakukan secara manual (paper based), infrastruktur jaringan belum memadai, memiliki jaringan internet dan komputer tetapi kurang memperhatikan aspek keamanan, belum memiliki aplikasi sistem informasi, SDM IT masih terbatas dan belum memiliki rencana strategis SI/TI. Oleh karena itu, dilakukan penelitian untuk menyusun rencana Strategis Sistem Informasi menggunakan pendekatan Ward and Peppard. Berdasarkan hasil analisis dan pembahasan direkomendasikan pengembangan beberapa aplikasi SI, yaitu: SI Pengelolaan Beasiswa, SI Pengarsipan dan Aset, SI Keuangan dan Penggajian SI Akuntasi, SI Eksekutif, Website dan SI Monitoring Evaluasi Penerima Beasiswa. Aplikasi tersebut 
direkomendasikan untuk dikembangkan secara bertahap selama 4 (empat) tahun disesuaikan dengan rencana induk organisasi. [3]

Penelitian dilakukan Yoki Firmansyah (2015), berjudul "Perencanaan Strategis Sistem Informasi Dan Teknologi Informasi Menggunakan Metode Ward and Peppard" (PT. Akcaya Utama Press Pontianak Post). PT Akcaya Utama Press adalah perusahaan yang berkonsentrasi pada bidang media massa terutama cetak media dengan produknya yaitu Pontianak Post di mana dalam menjalankan proses bisnisnya belum sepenuhnya menerapkan penggunaan SI/TI di perusahaan, meskipun seperti yang kita kenal sekarang atau di masa depan ada kebutuhan SI/TI untuk mengembangkan bisnis perusahaan. Metode yang digunakan dalam tesis ini adalah metode Ward and Peppard sebagai kerangka berpikir penulis sementara sebagai analisis penulis menggunakan beberapa teknik analisis. seperti Analisis SWOT, Analisis Rantai Nilai, KPI, McFarlan Strategic Grid, Five Force porter dan Pest Analysis [4]

\section{METODE PENELITIAN}

\subsection{Kajian Pustaka}

\subsubsection{Perencanaan Strategis Sistem Informasi}

Perencanaan strategis adalah proses manajerial yang meliputi pengembangan dan pemeliharaan suatu keserasian yang berlangsung terus antara sasaran-sasaran organisasi dengan sumber daya dan berbagai peluang yang terdapat di lingkungannya. Perencanaan Strategis adalah sebuah alat manajemen yang digunakan untuk mengelola kondisi saat ini untuk melakukan proyeksi kondisi pada masa depan, sehingga rencana strategis adalah sebuah petunjuk yang dapat digunakan organisasi dari kondisi saat ini untuk mereka bekerja menuju 5 sampai 10 tahun ke depan [5]

Perencanaan strategis SI/TI merupakan suatu proses identifikasi portofolio aplikasi berbasis komputer yang bertujuan untuk mendukung organisasi dalam pelaksanaan rencana bisnis dan merealisasikan tujuan bisnisnya. Perencanaan strategis SI/TI mempelajari pengaruh SI/TI terhadap kinerja bisnis dan kontribusi bagi organisasi dalam memilih langkah-langkah strategis [2]

Metodologi merupakan kumpulan dari metode, teknik, dan tools yang digunakan untuk mengerjakan sesuatu. Tujuan dari penggunaan metodologi dalam perencanaan strategis SI/TI adalah untuk meminimalkan resiko kegagalan, memastikan keterlibatan semua pihak yang berkepentingan serta meminimalkan ketergantungan individu, dan lebih menekankan kepada proses dan sasaran yang ditentukan.

Pendekatan metodologi versi Ward and Peppard ini dimulai dari kondisi investasi SI/TI di masa lalu yang kurang bermanfaat bagi tujuan bisnis organisasi dan menangkap peluang bisnis, serta fenomena meningkatkan keunggulan kompetitif suatu organisasi karena mampu memanfaatkan SI/TI dengan maksimal. [6]

\subsection{Tahapan Penelitian}

Metodologi penelitian yang digunakan adalah metodologi kualitatif, metode ini bertujuan untuk menggambarkan dan menjelaskan mengenai informasi yang ada di Dinas Perpustakaan dan Kearsipan Salatiga. Metode penelitian deskriptif diharapkan mampu menggambarkan suatu fenomena sosial dan memahami secara mendalam mengenai masalah yang ada di Dinas Perpustakaan dan Kearsipan Salatiga. Metode kualitatif bertujuan untuk memberikan informasi yang sesuai dengan fenomena yang ada sehingga diharapkan bermanfaat bagi perkembangan

Askar, et., al [Perencanaan Strategis Sistem Informasi Menggunakan Ward And Pepper (Studi Kasus Dinas Perpustakaan Dan Kearsipan Salatiga) 
ilmu pengetahuan dimasa yang akan datang kemudian metode penelitian ini dapat diterapkan di berbagai masalah. Tahapan terdiri dari:

1. Analisis lingkungan bisnis internal, yang mencakup aspek-aspek strategi bisnis saat ini, sasaran, sumber daya, proses, serta budaya nilai-nilai bisnis organisasi.

2. Analisis lingkungan bisnis eksternal, yang mencakup aspek-aspek ekonomi, industri, dan iklim bersaing perusahaan.

3. Analisis lingkungan SI/TI internal, yang mencakup kondisi SI/TI organisasi dari perspektif bisnis saat ini, bagaimana kematangannya (maturity), bagaimana kontribusi terhadap bisnis, keterampilan sumber daya manusia, sumber daya dan infrastruktur teknologi, termasuk juga bagaimana portofolio dari SI/TI yang ada saat ini.

4. Analisis lingkungan SI/TI eksternal, yang mencakup tren teknologi dan peluang pemanfaatannya, serta penggunaan SI/TI oleh kompetitor, pelanggan dan pemasok.

Sedangkan tahapan keluaran merupakan bagian yang dilakukan untuk menghasilkan suatu dokumen perencanaan strategis SI/TI yang isinya terdiri dari:

1. Strategi SI bisnis, yang mencakup bagaimana setiap unit/fungsi bisnis akan memanfaatkan SI/TI untuk mencapai sasaran bisnisnya, portofolio aplikasi dan gambaran arsitektur informasi.

2. Strategi TI, yang mencakup kebijakan dan strategi bagi pengelolaan teknologi dan sumber daya manusia SI/TI.

3. Strategi Manajemen SI/TI, yang mencakup elemen-elemen umum yang diterapkan melalui organisasi, untuk memastikan konsistensi penerapan kebijakan SI/TI yang dibutuhkan.

Beberapa teknik/metode analisis yang digunakan dalam perencanaan strategis SI/TI pada metodologi ini, mencakup analisis SWOT, analisis Five Forces Competitive, analisis Value Chain, metode Critical Succes Factors, metode Balanced Scorecard, dan McFarlan's Strategic Grid. [7]

\subsection{Metodologi Ward and Peppard}

Pendekatan metodologi versi Ward and Peppard ini dimulai dari analisis kondisi bisnis dan investasi SI/TI yang sudah berjalan yang dinilai kurang efektif, lalu menganalisa kondisi bisnis eksternal sehingga dapat meningkatkan keunggulan kompetitif suatu organisasi. Analisis pemanfaatan SI/TI apakah sudah maksimal, lalu membandingkannya dengan kecenderungan kondisi SI/TI yang digunakan di luar. Karena, terkadang kurang bermanfaatnya SI/TI bagi organisasi disebabkan SI/TI lebih fokus ke teknologi, bukan berdasarkan kebutuhan bisnis.

Berikut ini merupakan tahapan metodologi Ward and Peppard

\section{Analisis PEST}

Analisis PEST adalah analisis atau alat perencanaan strategis yang digunakan untuk mengevaluasi dampak dari faktor-faktor Politik, Ekonomi, Sosial dan Teknologi terhadap suatu proyek. Faktor Politik yang pada dasarnya adalah bagaimana campur tangan pemerintah dalam perekonomian [8]. Secara khusus, faktor-faktor politik termasuk: kebijakan pajak, hukum perburuhan, hukum lingkungan, pembatasan perdagangan, tarif, dan stabilitas politik. Faktor Ekonomi mencakup kondisi perekonomian saat ini dan dimasa yang akan datang yang dapat mempengaruhi kemajuan dan strategi usaha perusahaan. Faktor sosial terpusat pada penilaian dari sikap konsumen dan karyawan yang mempengaruhi strategi. Faktor Teknologi menganalisis dan menilai bagaimana teknologi dapat berdampak positif atau negatif terhadap pengenalan produk atau layanan ke pasar. Faktor ini termasuk kemajuan teknologi, siklus hidup teknologi, peran Internet, dan pengeluaran untuk penelitian teknologi oleh pemerintah. 


\section{Analisis Value Chain}

Analisa Value Chain dilakukan untuk memetakan seluruh proses kerja yang terjadi dalam organisasi menjadi dua kategori aktivitas, yaitu aktivitas utama dan aktivitas pendukung. Dalam tahap ini didefinisikan aktivitas-aktivitas didalam suatu organisasi yang mendukung tercapainya tujuan organisasi.

3. Analisis SWOT

SWOT adalah singkatan dari Strength, Weakness, Opportunity, Treats. Tujuan dari analisis SWOT adalah agar instansi/perusahaan menyadari 4 hal tersebut sesuai dengan hasil dari analisis lingkungan untuk mengetahui langkah strategis apa yang diambil demi mencapai hasil yang diinginkan dan menghindari hal yang tidak diinginkan. Dengan mengetahui kekuatan yang dimiliki instansi/organisasi akan dapat mempertahankan dan bahkan meningkatkan kekuatan yang telah dimiliki oleh instansi/perusahaan tersebut. Mengidentifikasi kelemahan bertujuan untuk dapat mengetahui apa kelemahan-kelemahan yang masih ada dan segera memperbaiki agar menjadi lebih baik kedepannya. Dengan mengetahui peluang, baik peluang saat ini maupun peluang dimasa yang akan datang, maka perusahaan dapat mempersiapkan diri untuk dapat mencapai peluang tersebut. Berbagai strategi dapat disiapkan lebih dini dan terencana dengan lebih baik sehingga peluang yang telah diidentifikasi dapat direalisasikan.

4. Analisis CSF

Analisa CSF merupakan suatu ketentuan dari organisasi dan lingkungannya yang berpengaruh pada keberhasilan atau kegagalan. CSF dapat ditentukan jika objektif organisasi telah diidentifikasi. Tujuan dari CSF adalah menginterpretasikan objektif secara lebih jelas untuk menentukan aktivitas yang harus dilakukan dan informasi apa yang dibutuhkan. Peranan CSF dalam perencanaan strategis adalah sebagai penghubung antara strategi bisnis organisasi dengan strategi SI-nya, memfokuskan proses perencanaan strategis SI pada area yang strategis, memprioritaskan usulan aplikasi SI dan mengevaluasi strategi SI.

5. McFarlan Grip Strategic

McFarlan Grip Strategic digunakan untuk memetakan aplikasi SI berdasarkan kontribusinya terhadap organisasi. Pemetaan dilakukan pada empat kuadran (strategic, high potential, key operation, and support). Dari hasil pemetaan tersebut didapat gambaran kontribusi sebuah aplikasi SI terhadap organisasi dan pengembangan dimasa mendatang, keempat kuadran tersebut dapat dilihat pada gambar dibawah ini. 


\begin{tabular}{|c|c|}
\hline STRATEGIC & HIGH POTENTLAL \\
\hline $\begin{array}{l}\text { Applications that } \\
\text { are critical to } \\
\text { sustaining future } \\
\text { business strategy }\end{array}$ & $\begin{array}{l}\text { Applications that } \\
\text { may be important } \\
\text { in achieving future } \\
\text { success }\end{array}$ \\
\hline $\begin{array}{l}\text { Applications on which } \\
\text { the organization } \\
\text { currently depends } \\
\text { for success }\end{array}$ & $\begin{array}{l}\text { Applications that } \\
\text { are valuable but } \\
\text { not critical to } \\
\text { success }\end{array}$ \\
\hline KEY OPERATIONAL & SUPPORT \\
\hline
\end{tabular}

Gambar 3. McFarlan Grip Strategic

\section{HASIL DAN PEMBAHASAN}

\subsection{Analisis PEST}

Dari hasil observasi dan wawancara yang dilakukan dengan Andis Permana Sari dari DINPERPUSDA Salatiga menjelaskan:

"Pendanaan yang kurang menjadi faktor yang mempengaruhi kondisi SI/TI di dalam DINPERSIPDA yang menyebabkan belum adanya perekrutan divisi IT yang bertugas bertugas melakukan pengembangan dan perawatan SI/TI. Akibat belum adanya divisi IT akhirnya ada aplikasi yang akhirnya tidak digunakan kembali karena telah diretas oleh hacker" (Sari, 2021)

Berdasarkan hasil observasi dan wawancara yang dilakukan dapat digambarkan empat faktor eksternal yang mempengaruhi SI/TI di lingkungan Dinas Perpustakaan dan Kearsipan Kota Salatiga:

1. Politik

- Peraturan perundang-undangan yang menjamin dan mengembangkan perpustakaan daerah dan memfasilitasi penyelenggaraan perpustakaan daerah.

2. Ekonomi

- Biaya maintenance yang masih kurang

3. Sosial

- Tidak Tersedianya tenaga IT yang kompeten

4. Teknologi

- Keamanan data yang masih kurang maksimal

\subsection{Analisis Value Chain}

Analisis Value Chain adalah analisis yang dilakukan untuk menggambarkan seluruh proses bisnis yang ada pada Dinas Perpustakaan dan Kearsipan untuk mencapai tujuannya, seperti dari hasil wawancara dengan Andis Permana Sari dari DINPERSIDA Salatiga menjelaskan 
"Aktivitas utama DINPERSIPDA ada 3 yaitu urusan perpustakaan, kearsipan dan pembinaan dan pengembangan sedangkan aktivitas pendukung yang dilakukan seperti pemeliharaan sarana dan prasarana seperti pembangunan taman baca dan pembangunan gedung arsip, pengelolaan SDM, pengelolaan SI/T, pengelolaan keuangan dan pengelolaan administrasi umum." (Sari, 2021)

Berdasarkan hasil dari wawancara dengan Andis Permana Sari dari DINPERSIPDA Kota Salatiga proses bisnis yang ada digolongkan menjadi 2 yaitu aktivitas utama dan aktivitas pendukung. Berikut ini adalah gambar dari analisis Value Chain

\begin{tabular}{|c|c|c|c|}
\hline \multirow{5}{*}{ 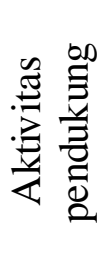 } & \multicolumn{3}{|c|}{ Pemeliharaan sarana dan prasana } \\
\hline & \multicolumn{3}{|c|}{ Pengelolaan Sumber Daya Manusia } \\
\hline & \multicolumn{3}{|c|}{ Pengelolaan SI/TI } \\
\hline & \multicolumn{3}{|c|}{ Pengelolaan Keuangan } \\
\hline & \multicolumn{3}{|c|}{ Pengelolaan Administrasi umum } \\
\hline 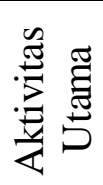 & $\begin{array}{l}\text { Pelayanan } \\
\text { bidang } \\
\text { kearsipan }\end{array}$ & $\begin{array}{l}\text { Pelayanan bidang } \\
\text { Pembinaan dan } \\
\text { Pengembangan }\end{array}$ & $\begin{array}{l}\text { Pelayanan } \\
\text { bidang } \\
\text { Perpustakaan }\end{array}$ \\
\hline
\end{tabular}

Gambar 4. Analisis Value Chain

Aktivitas pendukung:

a) Pemeliharaan sarana dan prasarana

b) Pengelolaan SDM

c) Pengelolaan SI/TI

d) Pengelolaan Keuangan

e) Pengelolaan Administrasi umum

Aktivitas Utama:

a) Pelayanan Bidang Kearsipan

b) Pelayanan Bidang Pembinaan dan Pengembangan

c) Pelayanan Bidang Perpustakaan

\subsection{Analisis SWOT}

Analisis SWOT (Strengths, Weaknesses, Opportunities, Threats) digunakan untuk menilai kekuatan dan kelemahan dari sumber daya yang dimiliki oleh Dinas Perpustakaan dan Kearsipan Kota Salatiga dan peluang eksternal dan tantangan yang yang dihadapi. Dari hasil wawancara yang dilakukan dengan Andis Permana Sari dari DINPERSIDA disampaikan bahwa:

"DINPERSIDA memiliki keunggulan yaitu tersedianya pelayanan secara online melalui aplikasi yang tersedia yang memudahkan pelayanan di masa pandemi ini, namun DINSPERSIPDA belum memiliki divisi IT sendiri dan belum memiliki server khusus yang bertugas menampung semua aplikasi. Karena belum memiliki divisi IT semua maintenance dilakukan oleh KOMINFO jadi jika ada aplikasi yang error harus menunggu dari kominfo terlebih dahulu." (Sari, 2021)

Seperti yang dikutip dari hasil wawancara diatas diambil kesimpulan bahwa implementasi SI/TI DINPERSIPDA sudah berjalan sesuai dengan proses bisnis namun masih memiliki 
kelemahan di bagian maintenance karena belum adanya divisi IT. Berikut adalah tabel analisis SWOT untuk memetakan lingkungan Internal/ Eksternal Bisnis.

Tabel 1. Analisis SWOT

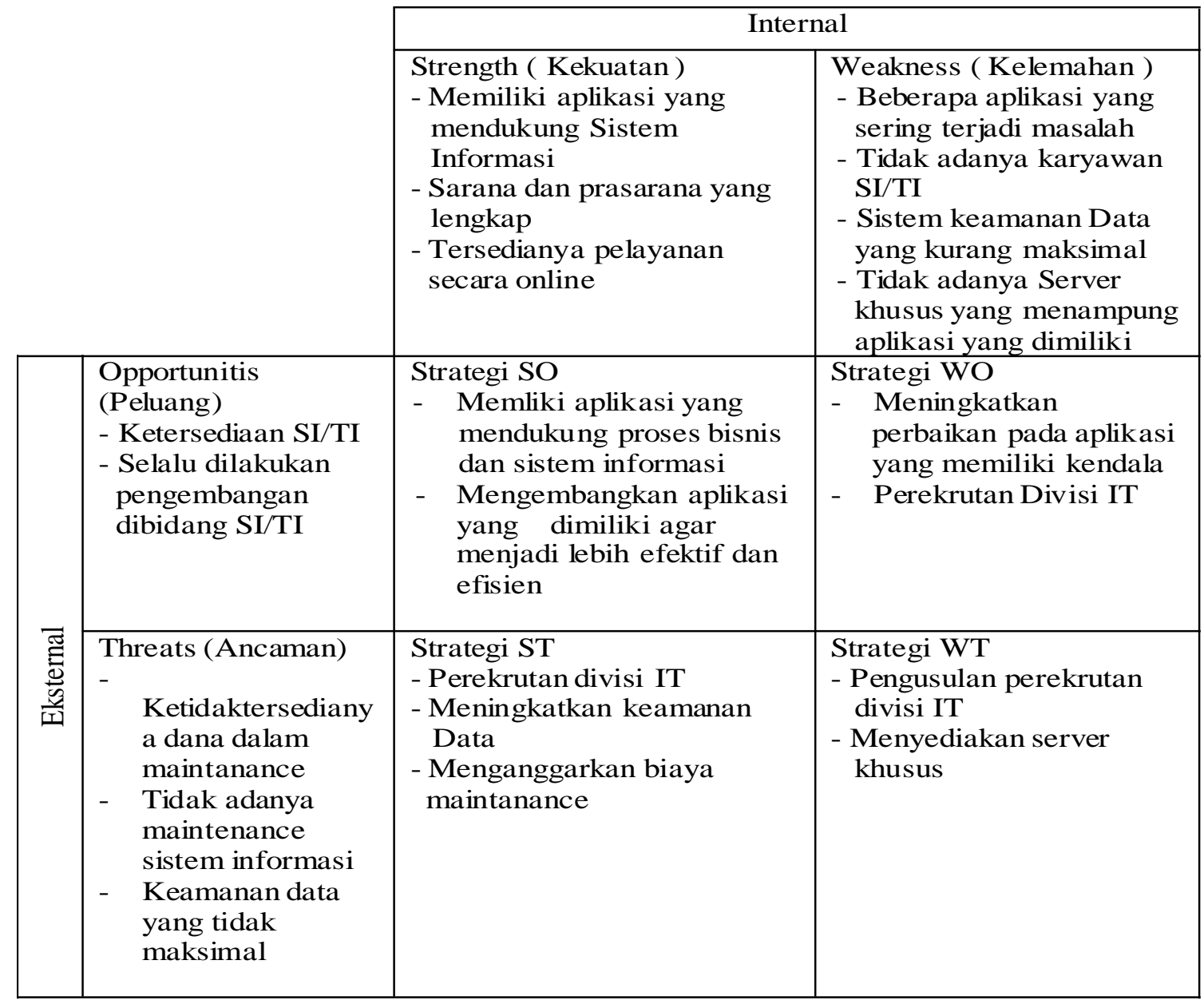

\subsection{Analisis CSF}

Analisis Critical Success Factor bertujuan untuk menginterpretasikan objektif secara lebih jelas untuk menentukan aktivitas yang harus dilakukan dan informasi apa yang dibutuhkan. Dalam penyusunan Analisis CSF dilakukan wawancara dengan narasumber Alwan Fauzan HS dari DINPERPUSDA Salatiga dijelaskan bahwa

"Pimpinan memiliki peran penting dalam penentuan keberhasilan, segala jenis keputusan yang ambil harus mendapat persetujuan dari pimpinan lalu bisa dikerjakan. Memberikan pelatihan terhadap SDM juga menjadi peran penting dalam penentu keberhasilan agar dapat memberikan pelayanan yang prima dan meningkatkan kinerja. (HS, 2021)

Berdasarkan dari hasil wawancara, dapat digambarkan bahwa pencapaian Visi dari Dinas Perpustakaan dan Kearsipan Kota Salatiga terletak pada peningkatan pelayanan yang diberikan. Pimpinan memiliki peran penting dalam penentuan keberhasilan, segala jenis keputusan yang ambil harus mendapat persetujuan dari pimpinan lalu bisa dikerjakan. Memberikan pelatihan terhadap SDM juga menjadi peran penting dalam penentu keberhasilan agar dapat memberikan pelayanan yang prima dan meningkatkan kinerja. 
Tabel 2. Analisis CSF

\begin{tabular}{|l|l|l|}
\hline $\begin{array}{l}\text { Misi Dinas Perpustakaan } \\
\text { dan Kearsipan Daerah } \\
\text { Salatiga }\end{array}$ & \multicolumn{1}{|c|}{$\begin{array}{c}\text { Faktor Penentu } \\
\text { Keberhasilan }\end{array}$} & \multicolumn{1}{c|}{ Tujuan Strategi } \\
\hline $\begin{array}{l}\text { Meningkatkan sarana dan } \\
\text { prasaran Perpustakaan dan } \\
\text { Kearsipan. }\end{array}$ & $\begin{array}{l}\text { Pemimpin yang menentukan } \\
\text { dan menyetujui segala jenis } \\
\text { usulan maupun perencanaan } \\
\text { untuk meningkatkan sarana } \\
\text { dan prasarana }\end{array}$ & $\begin{array}{l}\text { Mengikuti perkembangan } \\
\text { zaman untuk memberikan } \\
\text { yang terbaik untuk pemustaka } \\
\text { dengan pelayanan yang prima }\end{array}$ \\
$\begin{array}{l}\text { Meningkatkan kualitas Sumber } \\
\begin{array}{l}\text { Daya Manusia di bidang } \\
\text { Perpustakaan dan Kearsipan. }\end{array}\end{array}$ & $\begin{array}{l}\text { Adanya pelatihan untuk SDM } \\
\text { yang ada di DINPERSIPDA }\end{array}$ & $\begin{array}{l}\text { Untuk memberikan pelayanan } \\
\text { yang prima dan meningkatkan } \\
\text { kinerja DINPERSIPDA agar } \\
\text { lebih baik lagi }\end{array}$ \\
\hline $\begin{array}{l}\text { Menyelamatkan, memelihara, } \\
\text { dan mengamankan arsip sebagai } \\
\text { sarana informasi utama. }\end{array}$ & $\begin{array}{l}\text { Lembaga kearsipan daerah } \\
\text { berwenang untuk membina } \\
\text { dan mengkoordinasi seluruh } \\
\text { OPD dikota salatiga }\end{array}$ & $\begin{array}{l}\text { Untuk menyelamatkan arsip } \\
\text { agar dapat ditemukan kembali } \\
\text { dan menjadi sarana informasi } \\
\text { utama }\end{array}$ \\
$\begin{array}{l}\text { Menarik, memelihara, dan } \\
\text { melestarikan karya cetak dan } \\
\text { karya rekam hasil budaya } \\
\text { daerah Kota Salatiga. }\end{array}$ & $\begin{array}{l}\text { DINPERSIPDA berwenang } \\
\text { mengakusisi arsip-arsip yang } \\
\text { memiliki nilai sejarah dan } \\
\text { budaya kota Salatiga }\end{array}$ & $\begin{array}{l}\text { Untuk menyelamatkan } \\
\text { arsip-arsip bernilai sejarah } \\
\text { dan budaya kota salatiga } \\
\text { agara dapat menjadi } \\
\text { pembelajaran kepada } \\
\text { masyarakat tentang budaya } \\
\text { kota Salatiga. }\end{array}$ \\
\hline
\end{tabular}

\subsection{Portofolio Aplikasi}

Analisis ini akan memanfaatkan teori McFarlan Grip Strategis. Analisi McFarlan digunakan untuk mengetahui peran aplikasi yang digunakan oleh DINPERSIPDA. Dengan adanya analisis MCFarlan maka sistem informasi yang ada dapat dipetakan menjadi 4 kuadrat sehingga dapat melakukan perencaan lebih lanjut agar memanfaatkan potensi SI/TI yang sebesar-besar sehingga proses bisnis dapat berjalan secara maksimal. Dalam penyusunan McFarlan Grip Strategic diperlukan portofolio aplikasi yang dimiliki oleh Dinas Perpustakaan dan Kearsipan Kota Salatiga oleh karena itu dilakukan wawancara dengan narasumber Alwan Fauzan dari DINPERSIPDA yang menjelaskan:

"Didalam Dinas Perpustakaan dan Kearsipan Kota Salatiga memiliki beberapa aplikasi yaitu: Aplikasi SLIMS, Aplikasi SKD, Aplikasi I-Salatiga, Aplikasi SIKANO, Aplikasi Salatiga Aplikasi SIAVI,Aplikasi Siap Online, Aplikasi Pinjamarsip,Aplikasi OPAC, Mobile Library.” (HS, 2021)

Berdasarkan hasil penyusunan kebutuhan aplikasi SI/TI di Dinas Perpustakaan dan Kearsipan Kota Salatiga, maka terbentuklah aplikasi portofolio yang dibentuk kedalam bentuk Strategic Grid McFarlan Analysis, yang digolongkan berdasarkan dampak aplikasi tersebut yaitu strategic, key operational, high potensial dan support. 
Tabel 3. Portofolio Aplikasi

\begin{tabular}{c|c|}
\hline Stortegic & High Potential \\
\hline Aplikasi SLIMS (Penustakaan) \\
Aplikasi SKD (Kearsipan) \\
Aplikasi dataperpus & Aplik asi I-Salatiga \\
& Aplikasi SIKANO \\
& Aplikasi SIAVI \\
& Aplikasi Siap Online \\
Aplikasi Pinjamarsip \\
Aplikasi OP AC \\
Aplikasi I-Salatiga & Aplik asi Salatiga Mobile Library \\
\hline AplikasiSalatiga Mobile Library & E mail \\
\hline Key Operational & Website \\
\hline
\end{tabular}

\subsection{Usulan SI/TI Strategic Planning}

\subsubsection{Strategic Bisnis SI}

Fokus DINPERSIPDA adalah pelayanan kepada masyarakat dan penyelamatan kearsipan. Berdasarkan analisis SWOT, situasi SI/TI dalam Dinas Perpustakaan dan Kearsipan sudah sangat baik namun yang menjadi kendala adalah keamanan data yang belum maksimal dan tidak adanya divisi IT. Pada kondisi ini DINPERSIPDA harus melakukan perekrutan divisi IT yang bertugas untuk merencanakan Pengembangan dan perawatan SI/TI agar proses bisnis dapat berjalan dengan lancar.

\subsubsection{Strategic Manajemen SI/TI}

Berdasarkan analisa yang dilakukan ditemukan bahwa di dalam Dinas Perpustakaan dan Kearsipan Kota Salatiga belum memiliki divisi khusus yang mengatur SI/TI di dalam DINPERSIPDA dan masih dikelola oleh KOMINFO, dan hal itu menyebabkan tidak maksimalnya perkembangan SI/TI yang ada di DINPERSIPDA, contoh saja halnya adanya aplikasi yang diretas dan akhirnya tidak pakai kembali dan adanya beberapa aplikasi yang mengalami gangguan oleh karena itu dibutuhkan sebuah divisi baru yang mempunyai tugas khusus mengelola IT.

Dengan adanya penambahan divisi IT pada DINPERSIPDA maka mulai dari perencanaan, pengembangan, penerapan dan kontrol pemeliharaan SI/TI pada DINPERSIPDA akan lebih terkontrol dan lebih efektif. Adapun tugas utama dari divisi IT pada DINPERSIPDA yaitu merencanakan Pengembangan dan perawatan SI/TI.

\section{KESIMPULAN}

Berdasarkan analisis dari hasil penelitian yang dilakukan dapat diambil kesimpulan bahwa implementasi SI/TI pada DInas Perpustakaan dan Kearsipan Kota Salatiga sudah berjalan dengan baik dan sesuai dengan proses bisnis yang ada namun yang menjadi masalah adalah belum adanya maintenance dan sistem keamanan data yang dimiliki belum maksimal. Hal itu terjadi karena DINPERSIPDA belum memiliki divisi IT yang bertugas untuk merancang pengembangan dan perawatan SI/TI hal itu menyebabkan banyaknya aplikasi yang belum bekerja secara efektif maupun efisien dan karena belum adanya server khusus yang bertugas menampung seluruh SI/TI di DINPERSIPDA oleh karena itu jika terdapat masalah pada 
aplikasi harus diserahkan ke KOMINFO terlebih dahulu untuk dilakukan perbaikan dan itu membutuhkan waktu yang lumayan lama.

\section{SARAN}

Untuk mendukung hal tersebut maka penelitian ini merekomendasikan untuk melakukan perekrutan Divisi IT yang bertugas melakukan maintenance rutin pada SI/TI dan membuat server khusus untuk menampung semua perangkat yang terdapat di dalam DINPERSIPDA.

Melalui penelitian diharapkan dapat menyelesaikan masalah yang terjadi di dalam DINPERSIPDA baik secara internal maupun eksternal secara khusus SI/TI sehingga dapat meningkatkan mutu pelayanan kepada masyarakat.

\section{DAFTAR PUSTAKA}

[1] Ari Wedhasmara. 2017, "Langkah-langkah Perencanaan Strategis Sistem Informasi Dengan Menggunakan Metode Ward and Peppard | Wedhasmara | Jurnal Sistem Informasi," Jsi, Vol. 1 No. 1, pp. 14-22, [Online]. Available: https://ejournal.unsri.ac.id/index.php/jsi/article/view/704.

[2] F. Wibowo and A. F. Wijaya, 2018, "Perencanaan Strategis SI/TI Menggunakan Metode Ward and Peppard (Studi Kasus: Sinode GKJ)," Semin. Nas. Sist. Inf. Indones., No. November, pp. 39-44.

[3] D. Wandikbo and M. N. N. Sitokdana, "Perencanaaan Strategis Sistem Informasi di Yayasan Binterbusih Semarang Menggunakan Ward and Peppard,” No. 1, pp. 61-69, 2019.

[4] Y. Firmansyah, "Jurnal khatulistiwa informatika, Vol. 3, No.1 Juni 2015," $J$. Khatulistiwa Inform., Vol. 3, No. 1, pp. 105-118, 2015, [Online]. Available: http://ejournal.bsi.ac.id/ejurnal/index.php/khatulistiwa/article/download/2304/1597.

[5] Harold Kerzren, A System to Planning, Scheduling and Controlling, Vol. 34, No. 12. 2001.

[6] Y. A. Setyono, A. F. Wijaya, and M. N. N. Sitokdana, "Perencanaan Strategis Sistem Informasi Menggunakan Ward and Peppard (Studi Kasus: Gereja Kristen Jawa Plengkung ),” 2018.

[7] A. M. Indra Purnama and G. Noviana, "Perencanaan Strategis Sistem Informasi Menggunakan Metode Ward and Peppard (Studi Kasus: Universitas Sangga Buana YPKP Bandung)," Infotronik J. Teknol. Inf. dan Elektron., Vol. 5, No. 2, p. 84, 2020, doi: 10.32897/infotronik.2020.5.2.491.

[8] V. R. B. Prawestri and A. F. Wijaya, "Penerapan Metodologi Tozer Dalam Perencanaan Strategis Sistem Informasi pada PT. Telekomunikasi Indonesia Tbk Witel Bandung," J. Comput. Inf. Syst. Ampera, Vol. 1, No. 2, pp. 112-132, 2020, doi: 10.51519/journalcisa.v1i2.34. 